ISSN 1112-9867

\title{
STABILITY PROPERTIES OF ASPHALT MIXTURE INCORPORATING COCONUT SHELL
}

\author{
H. Yaacob ${ }^{1}$, R. P. Jaya ${ }^{1,}{ }^{,}$, A. H. Madzaili ${ }^{1}$, N. A. Hassan ${ }^{1}$, M. R. Hainin ${ }^{1}$ and F. M. Nazri ${ }^{2}$ \\ ${ }^{1}$ Faculty of Civil Engineering, Department of Geotechnics and Transportation, Universiti \\ Teknologi Malaysia, 81310 Johor Bahru, Malaysia \\ ${ }^{2}$ School of Civil Engineering, Universiti Sains Malaysia, Engineering Campus, 14300 Nibong \\ Tebal, Penang, Malaysia
}

Published online: 10 November 2017

\begin{abstract}
This study aims to evaluate the effect of coconut shell at varying percentages as an aggregate replacement on the stability properties of the asphalt mixture. The performance of the specimen was evaluated through stability, stiffness, density and flow tests. Five coconut shell percentages namely $0 \%, 10 \%, 20 \%, 30 \%$ and $40 \%$ by weight volumes were used as aggregate replacements in asphaltic concrete. The mixture design incorporating the penetration grade 60/70 bitumen was used for specimen testing. The optimum content of bitumen for asphalt mixtures was 5\%. Test results showed that the stability, stiffness, density and flow of specimen increased with the increase of coconut shell content to a peak level $(10 \%)$ and then decreased with further additions of coconut shell. Results also indicated that $10 \%$ coconut shell was the optimum replacement as an aggregate in the asphaltic concrete.
\end{abstract}

Keywords: stability; coconut; stiffness; density; flow.

Author Correspondence, e-mail: ramadhansyah@utm.my

doi: http://dx.doi.org/10.4314/jfas.v9i6s.2 


\section{INTRODUCTION}

Coconut palm is highly valued and called "the tree of life" due to its various purposes [1]. Fruit-bearing palms are native to Malaysia, Polynesia, and southern Asia. Coconut byproducts have been widely used for a considerably long time and become a source of income for people. Agricultural waste can be treated by recycling the disposed material. Coconut is prominent as a multifunctional plant because all of its parts can be used for a wide-range of activities. The shell, husk, root, frond, flower and wood of the trunk also become convenient products [2]. In Malaysia, coconut is the fourth important industrial crop after oil palm, rubber and paddy in terms of the total planted area [3]. Coconut shell (CS) is an agricultural waste and available in large quantities throughout tropical countries worldwide. CS can be a high-end replacement material for housing construction [4]. Building materials from agricultural and forest wastes are suitable for low-cost housing because they are cheaper compared with regular materials [5]. Coconuts are present in a wide variety of size, weight, shape and color, depending on the genetic variety and maturity of the nut at harvest. Numerous studies have been conducted to improve and upgrade the materials for preparing hot asphalt mixture [6-8]. Utilizing waste material as a replacement for producing hot asphalt mixture can provide considerable benefits to humans [9]. CS is an alternative that can be used to replace an aggregate in preparing a flexible pavement [10]. CSs have also been used previously in building houses [11], ceiling and wall and in ceramic and mosaic production [12]. These uses show that the demand of the natural aggregate is remarkably high. Therefore, CS can be used to replace natural aggregate in the road construction of the wearing course.

\section{EXPERIMENTAL PROCEDURE}

\subsection{Materials}

Bitumen with the penetration grade of $60 / 70$ was used as the binder. The bitumen was oven heated until it became fluid before adding it to the aggregate mixture. Furthermore, two aggregate types namely granite and CS were used. Granite is nearly always massive (lacking internal structures), hard and tough, thereby gaining widespread use in construction [13]. In the present study, the CSs were already cracked by $50-100 \mathrm{~mm}$ but the fiber and coconut meat were still intact. They were sun dried for $24 \mathrm{~h}$ before the fibers were removed using a cutter. 
Some of the shells were crushed manually using a pestle and mortar. Afterward, other shells were crushed using an aggregate crushing machine. The CSs were sieved according to the JKR specification [14] as illustrated in Fig. 1. Table 1 provides a guide on mixing designation.

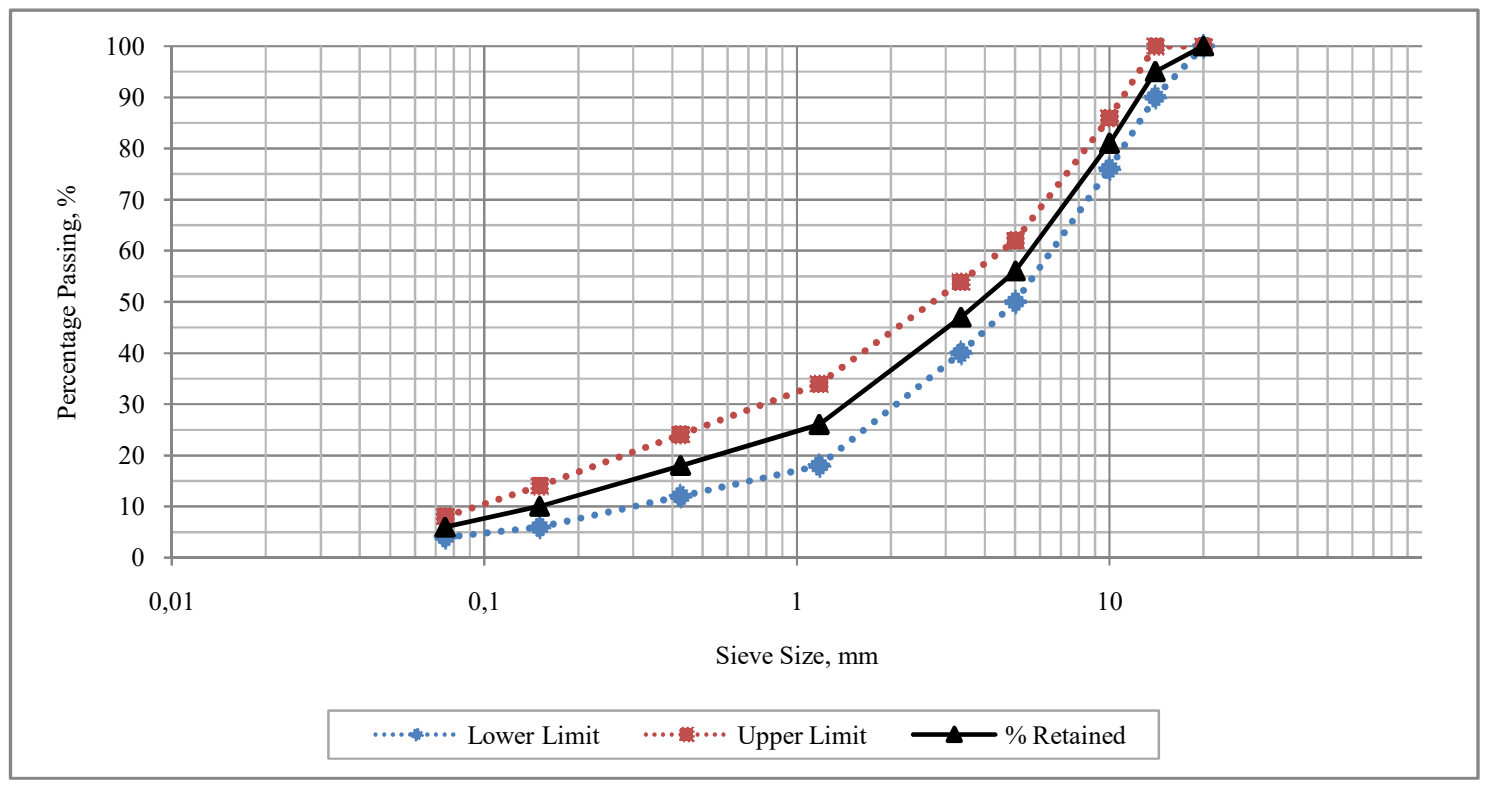

Fig.1.Gradation limit for asphaltic concrete [14]

Table1.Mix designation of specimens

\begin{tabular}{ccc}
\hline Mix Design & Coconut Shell (\%) & Designation \\
\hline & 0 & AC-CS0 \\
Asphaltic & 10 & AC-CS10 \\
Concrete & 20 & AC-CS20 \\
& 30 & AC-CS30 \\
& 40 & AC-CS40 \\
\hline
\end{tabular}

\subsection{Marshall Mixture Design}

Typical $101.6 \mathrm{~mm}$-inner diameter steel Marshall molds were used with the Marshall hammer. An electrically heated paddle mixer was used to blend the aggregates, CS and bitumen. The aggregate, bitumen and CS were mixed and compacted at $180 \pm 0.5^{\circ} \mathrm{C}$ in the laboratory. A $5 \%$ bitumen content was selected as the optimum value. The mixtures were compacted with 75 blows on each side using the standard Marshall hammer to avoid material disintegration. After compaction, the specimens were removed from the molds and allowed to cool down.

\subsection{Stability Test}

The stability value of each test specimen was determined in accordance with the ASTM D6927 [15]. For the stability test, the specimens were immersed in a water bath at a 
temperature of $60 \pm 1^{\circ} \mathrm{C}$ for a period of $45 \mathrm{~min}$. Subsequently, the specimens were placed in the Marshall Stability testing machine and loaded at a constant rate of deformation of 50.8 $\mathrm{mm} / \mathrm{min}$ until the maximum load was attained.

\section{RESULTS AND DISCUSSION}

\subsection{Stability, Stiffness and CS}

The relationship between the stability and stiffness of the asphaltic concrete at different percentages of CS is graphically presented in Fig. 2. All specimens behaved similarly; the stability of mixture initially increased to approximately $10 \%$ CS and then began to decrease until $40 \%$ CS. The increased stability in the initial stages resulted from the combined effect of the bitumen and CS. High stability values indicate the stiff and resistant mixtures [10]. The results also showed that the rate of increase in stability regarding the CS content of the asphalt concrete mix was higher than that of the conventional mix. For example, the maximum stability for $0 \%$ CS was $23 \mathrm{kN}$. However, a 10\% CS specimen exhibited a maximum stability of $125 \mathrm{kN}$. This result indicated that adding $10 \% \mathrm{CS}$ to the asphaltic concrete can increase the stability three times. Furthermore, the decrease in stability was mainly due to the high water absorption of the CS. The results of the stiffness tests on the asphalt mixture containing the $\mathrm{CS}$ at varying percentages are depicted in Fig. 2. Generally, the specimen stiffness increased when the CS content increased to a peak level (10\%) and then decreased with further additions of CS. The results also indicated that the CS10 asphalt mix exhibited the highest stiffness compared with those of CS0, CS20, CS30 and CS40. However, at $40 \% \mathrm{CS}$, the stiffness decreased to a value lower than that of the controlled mixture. Thus, a $10 \% \mathrm{CS}$ in an asphaltic concrete was considered the optimal limit. 


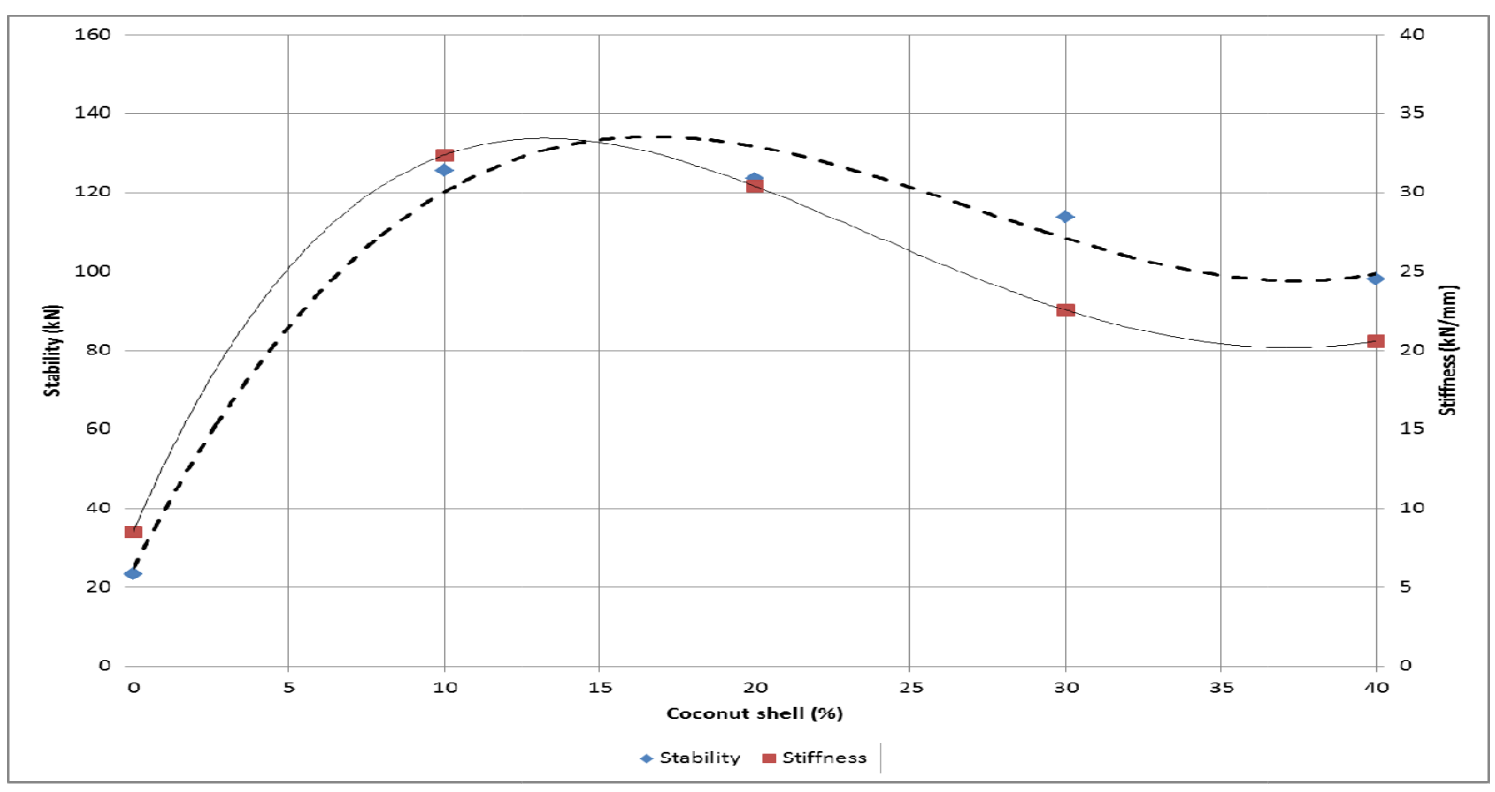

Fig.2. Stability and stiffness versus coconut shell

\subsection{Stability, Flow and CS}

The correlation among the stability, flow and CS at different contents is illustrated in Fig. 3. The AC-CS10 specimen recorded high stability and the lowest stability was at $40 \% \mathrm{CS}$. The stability of the mixture depends on the cohesion of bitumen, where the bonding capability increases with increasing bitumen content [16-17]. AC-CS40 is considerably easy to crack and brittle where it cannot stand high load. Therefore, AC-CS40 presented low strength. Moreover, the flow for the corresponding percentage of the CS increased proportionally. A high percentage of the CS replacement increased the flow, except for CS20. This result is due to a large number of voids presented in the specimen, thereby the easy cracking during loading. In general, AC-CS40 showed high flow where AC-CS0 recorded the lowest flow value. 


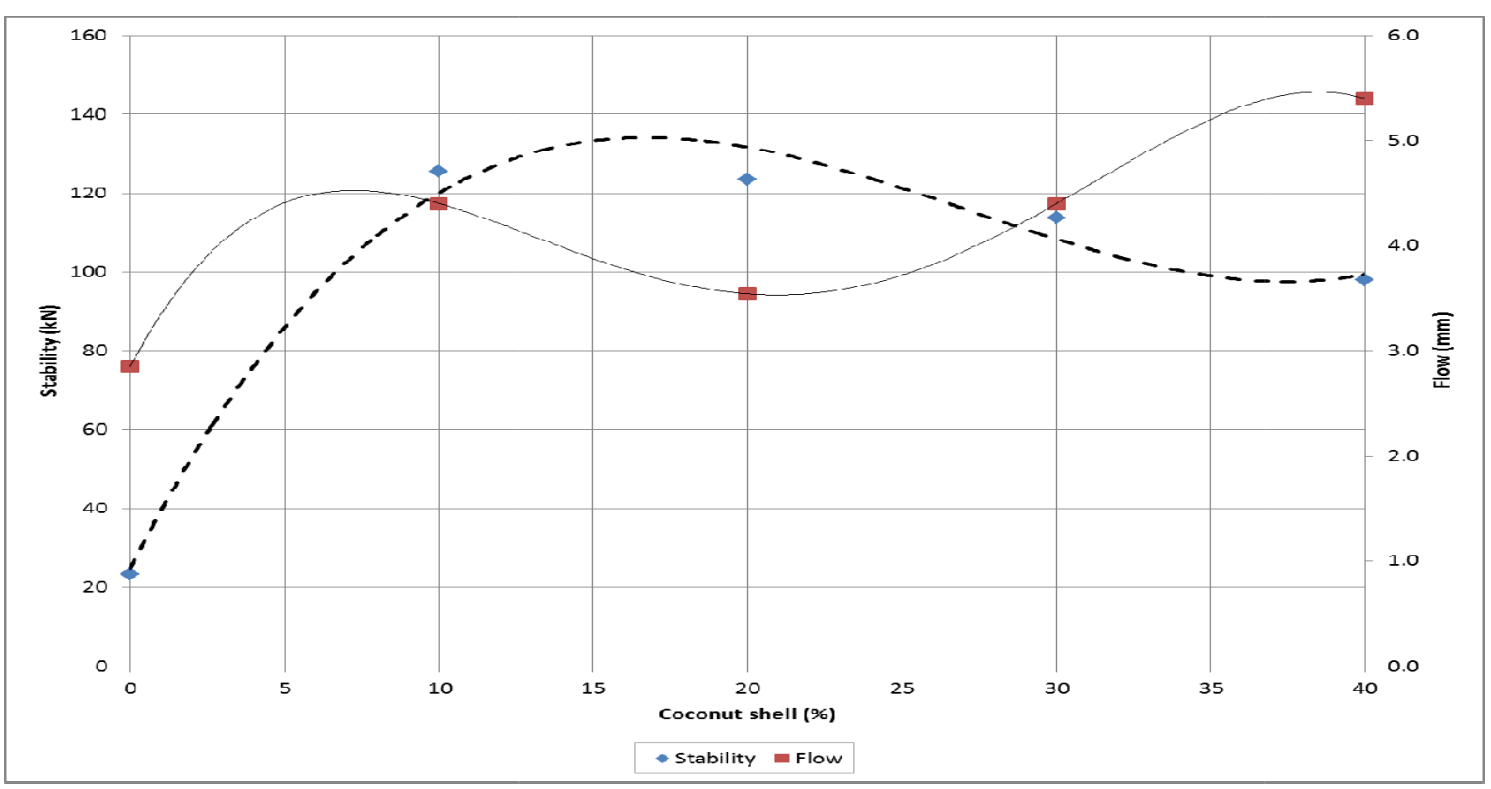

Fig.3. Stability and flowversus coconut shell

\subsection{Stability, Density and CS}

The relationship among stability, density and CS at varying percentages is plotted and shown in Fig. 4. The stability of the asphaltic concrete containing CS increased with the densities increasing to a peak level (10\%), and then decreased at $20 \%$ CS. Nevertheless, the density initially increased with further additions of CS. For instance, the density of $2.349-2.362 \mathrm{~g} / \mathrm{cm}^{3}$ was achieved when the CS percentage was increased from $0 \%$ to $10 \%$. The different content levels of CS can affect the density and stability of the mixture. Finally, the high density of mixes is probably due to the higher specific gravity of the natural aggregate compared with that of CS. 


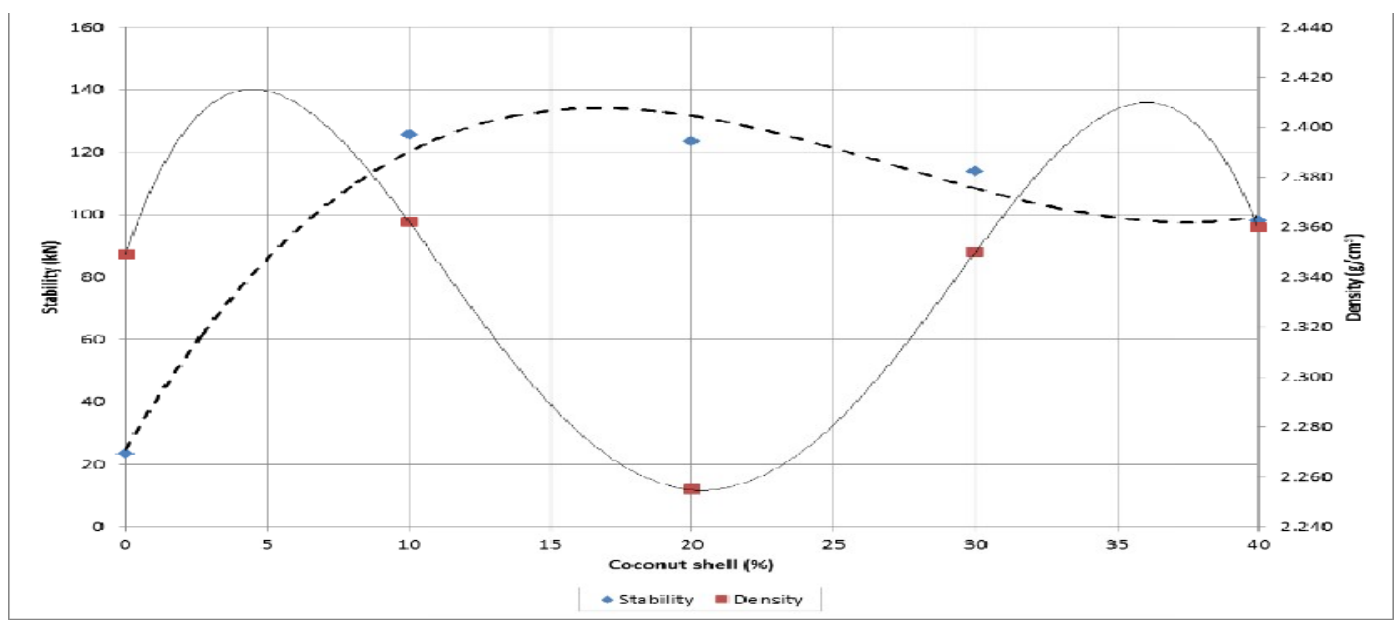

Fig.4. Stability and densityversus coconut shell

\subsection{Stability, Density and CS}

Fig. 5 presents a graphical illustration of the stiffness, density and CS in asphalt mixture. In general, the stiffness of CS asphalt mixture was almost similar to that in the stability test. The stiffness value of the asphaltic concrete initially increased when the CS content increased from $0 \%$ to $10 \%$, and then started to decrease until the specimens eventually deteriorated after a 40\% CS. High stiffness values indicated hard and remarkably resistant mixtures.

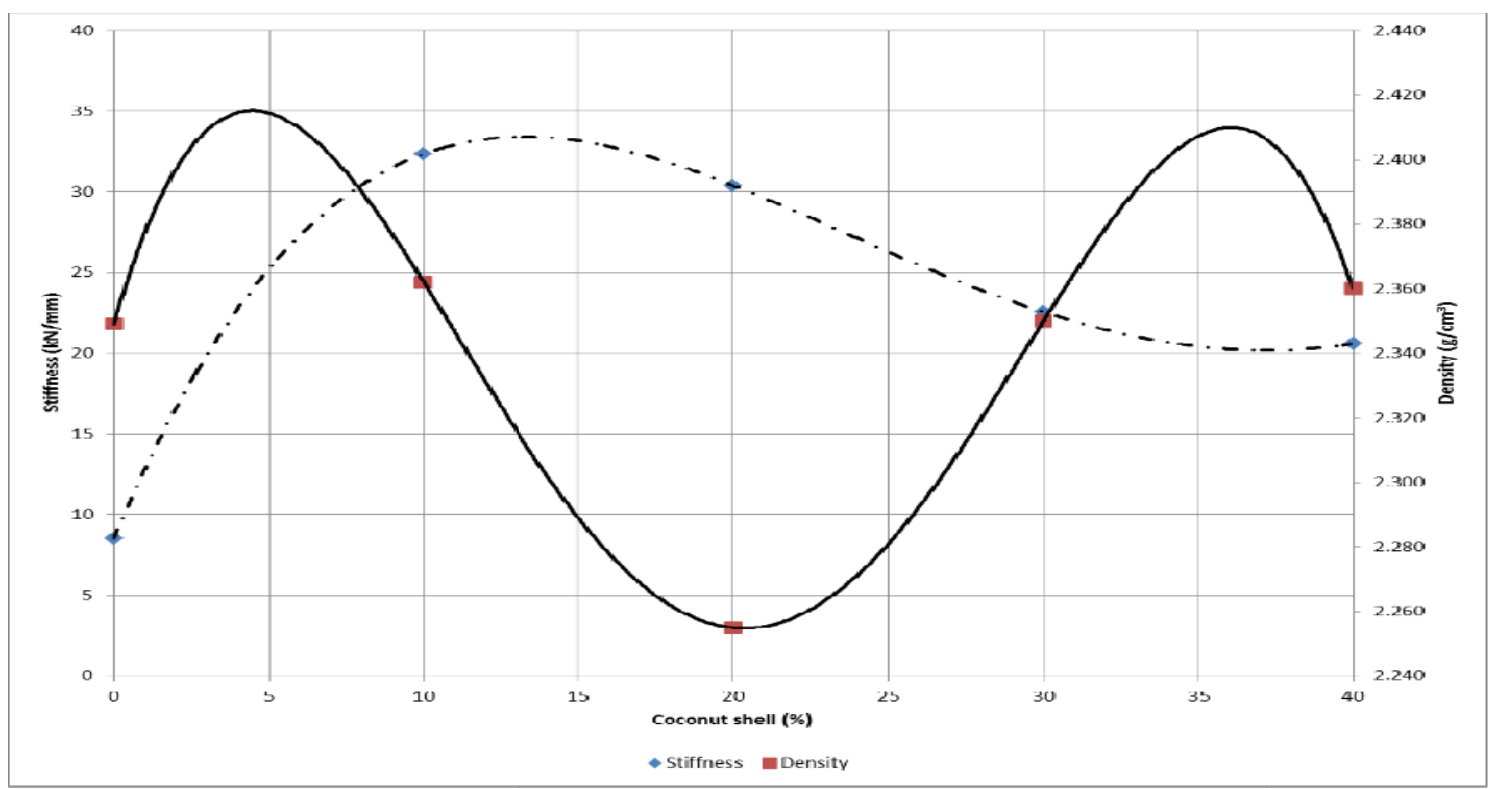

Fig.5.Stiffness and densityversus coconut shell 


\section{CONCLUSION}

Replacing conventional aggregate with certain amounts of CS effectively improved the stability properties of the asphaltic concrete. The optimum replacement percentage was $10 \%$. In addition, a CS can be satisfactorily used as an aggregate replacement material for increasing the performance of the asphaltic concrete.

\section{ACKNOWLEDGEMENTS}

The support provided by Malaysian Ministry of Higher Education and UniversitiTeknologi Malaysia in the form of a research grant vote no. Q.J130000.2522.14H30 and Q.J130000.2522.11H58 for this study is highly appreciated.

\section{REFERENCES}

[1] Gunasekaran K, KumarP S, Lakshmipathy M. Mechanical and bond properties of coconut shell concrete.Construction and Building Materials,2011, 25:92-98

[2] MannanM A, Ganapathy C. Engineering properties of concrete with oil palm shell as coarse aggregate.Construction and Building Materials,2002, 16:29-34

[3] RamadhansyahP J, Nurfatin A M, Siti N A J, Norhafizah M, NorhidayahA H, DewiS J. Use of coconut shell from agriculture waste as fine aggregate in asphaltic concrete, ARPN Journal of Engineering and Applied Sciences, 2016, 11(12):7457-7462

[4] OlanipekumE A, OlusolaK O, Ata O. A comparative study of concrete properties using coconut shell and palm kernel shell as coarse aggregates.Building and Environment, 2006, 41(3):297-301

[5] MannanM A, Ganapathy C. Concrete from an agricultural waste-oil palm shell (OPS).Building and Environment, 2004, 39(4):441-448

[6] Yaacob H, Ali MM, JayaR P, HaininM R, JayantiD S, Che WC N. Rheological properties of styrene butadiene rubber modified bitumen binder. JurnalTeknologi,2016, 78:(7-2):121-126 [7] AzaharW N A W, Bujang M, JayaR P, HaininM R, Ngadi N, AbdullahM M A B.Performance of waste cooking oil in asphalt binder modification. KeyEngineering Materials,2016, 700:216-226

[8] HaininM R, AzizM MA, AdnanA M, HassanN A, JayaR P, LiuH Y. Performance of 
modified asphalt binder with tire rubber powder. JurnalTeknologi, 2015, 73(4):55-60

[9] TingT L, JayaR P, HassanN A, Yaacob H, JayantiD S, AriffinM A M. A review of chemical and physical properties of coconut shell in asphalt mixture. JurnalTeknologi, 2016, 78(4):85-89

[10]JeffryS N A, Jaya RP, Manap N, MironN A, HassanN A. The influence of coconut shell as coarse aggregates in asphalt mixture. Key Engineering Materials,2016, 700:227-237

[11]Gunasekaran K, Ramasubramani R, Annadurai R, Chandar S P. Study on reinforced coconut shell concrete beam behavior under torsion.Materials and Design,2014, 57:374-382

[12]BasriH B. Concrete using waste oil palm shells as aggregate.Cement and Concrete Research,1999, 29(4):619-622

[13]Norhafizah M, Ramadhansyah P J, Amiera S N, Aqeela N M, Norhidayah A H, Hainin M R, Norazman C C.The effect of coconut shell on engineering properties of porous asphalt mixture. JurnalTeknologi,2016, 78(7-2):127-132

[14]Malaysian Public Works Department (JKR). Standard specification for road works section 4: Flexible pavement.Kuala Lumpur: JKR, 2008

[15]American Society for Testing and Materials (ASTM). ASTM D6927: Standard test method for Marshall Stability and flow of bituminous mixtures. Pennsylvania: ASTM, 2015 [16]Hassan N A, Airey G D, Yusoff N I, Hainin M R, Putrajaya R, Abdullah M E, Aziz M M. Microstructural characterisation of dry mixed rubberised asphalt mixtures. Construction and Building Materials, 2015, 82:173-183

[17]Nur HA H, NorH M, RamadhansyahP J. Effect of open-graded coarse aggregate on concrete paving blocks properties for pavement. ARPN Journal of Engineering and Applied Sciences, 2016, 11(20):11836-11839

\section{How to cite this article:}

Yaacob H, Jaya R P, Madzaili A H, Hassan N A, Hainin M R, Nazri F M. Stability properties of asphalt mixture incorporating coconut shell. J. Fundam. Appl. Sci., 2017, 9(6S), 16-24. 